\title{
NDT ASSESSMENT OF EXISTING CONCRETE STRUCTURES: SPATIAL ANALYSIS OF REBOUND HAMMER RESULTS RECORDED IN-SITU
}

\author{
Adorján BOROSNYÓI \\ Department of Construction Materials and Technologies, Budapest University of Technology and Eco- \\ nomics (BME), H-1111 Budapest, Muegyetem rkp. 3, Hungary
}

Received 12 June 2015; accepted 18 August 2015

\begin{abstract}
A comparative spatial analysis of surface hardness of structural concrete is introduced. Main objective of the paper is to make a repeatability comparison of three types of the still most popular non-destructive testing devices for concrete: L-type original Schmidt rebound hammer, $N$-type original Schmidt rebound hammer and N-type Silver Schmidt rebound hammer. Results indicate that the surface hardness measurement uncertainty is related to the weight of the hammer mass and is apparently not related to the impact energy of the rebound hammer devices. It is observed that the measure of surface hardness for the Silver Schmidt rebound hammer (Q-value) does not have positive correlation to the original rebound index (R). Results indicate the best performance of the N-type original Schmidt rebound hammer in terms of stability and normality of data. Geostatistical analysis of the measured data (in terms of empirical semivariograms) highlights different statistical behaviour for the mechanical recording rebound hammers and for the electro-optical recording rebound hammer.
\end{abstract}

Keywords: concrete, surface hardness, rebound hammer, repeatability, spatial analysis.

\section{Introduction}

Non-destructive testing (NDT) methods are powerful tools for the structural assessment of existing concrete structures during maintenance or before repair (Bungey et al. 2006; Malhotra, Carino 2004; ACI 2003; 2013). Material properties obtained by NDT methods allow collecting information about the near surface properties of concrete (e.g. electrical resistance, permeability, surface hardness, ultrasound pulse velocity etc.) that may provide the possibility of estimation of further characteristics (e.g. compressive strength) under special conditions (Malhotra 1976). The mostly used NDT method for the assessment of the surface hardness of structural concrete is the rebound hammer method (Schmidt 1950; Kolek 1958; Szilágyi et al. 2011; 2014). Rebound hammers (also called Schmidt hammer or Swiss hammer) are in worldwide use from the 1950's. Operating principle of the rebound hammer is the following: a spring accelerated mass is sliding along a guide bar and impacts one end of a steel plunger of which far end is compressed against the concrete surface tested (Szilágyi et al. 2015). The impact energy is constant for a given testing device, since the tensioning of the spring during operation is automatically released at a maximum position before impact. The hammer mass impacts the plunger of the device by the elastic energy released from the tensioned spring. After the impact, the hammer mass rebounds from the plunger and moves an index rider during rebound. Rebound indices are recorded by different methods in the rebound hammers. Original Schmidt rebound hammers (of which design is practically un-

Corresponding author:

A. Borosnyói E-mail: borosnyoi.adorjan@epito.bme.hu 
changed from 1954) record the rebound index (R): the ratio of paths driven by the hammer mass before impact and during rebound. Digitally recording rebound hammers (e.g. Digi-Schmidt) record the same rebound index $(\mathrm{R})$ but readings are collected digitally and not by visual reading of the operator. Digitally recording rebound hammers that record the coefficient of restitution (referred as Q-value) are also available (e.g. Silver Schmidt), but the measure of surface hardness is the ratio of velocities of the hammer mass just before and right after the impact, rather than the ratio of paths driven by the hammer mass. This latter measure $(\mathrm{Q})$ has not been satisfactorily proved to be related to the original rebound index (R), nevertheless specific publications has given such claims (Proceq 2007; Brandestini 2012). Impact energy of original Schmidt rebound hammers, Digi-Schmidt rebound hammers and Silver Schmidt rebound hammers can be either $2.207 \mathrm{Nm}$ (N-type) or $0.735 \mathrm{Nm}$ (L-type).

The operating principle of the rebound hammers makes possible to collect direct information about the damping properties of the concrete near to the surface that can be related to the compressive strength of concrete. When the hammer mass impacts the plunger, a compression stress wave starts to propagate toward the concrete within the plunger. The plunger deforms elastically during the stress wave propagation. When the compression stress wave reaches the fixed end of the plunger (i.e. the concrete), part of the energy is absorbed in the concrete and the rest of the stress wave is reflected back in the plunger. The reflected compression wave returns to the free end of the plunger and accelerates the hammer mass to rebound. The absorbed energy at the fixed end results local crushing of the concrete. The elastic deformation of the concrete recovers when the acceleration of the plunger is brought to rest and a residual set is formed in the concrete under the tip of the plunger. The energy absorbed in the concrete during the impact can be related to the compressive strength of concrete under certain conditions.

Assessment of concrete structures by rebound hammer is easy to be performed and does not require special preparations. Operators can collect measured values relatively fast and the data analysis is not time consuming either, especially for the digitally recording devices that are provided with data analysis software. Due to the advantages, rebound hammers are expected to remain the most popular devices for the assessment of surface hardness of structural concrete.

\section{Repeatability of rebound hammer testing}

Structural concrete is a multiple-level heterogeneous composite material. On a macro-level, its heterogeneity is derived from concrete construction practice, i.e. random differences of compaction and curing at different spatial locations, possible non-uniform supply of material and structural effects (reinforcement, changes in dimension or shape, connecting structural elements). On a meso-level, its heterogeneity is derived from concrete composition, i.e. type and grading of coarse aggregate and the paste content of fresh concrete. On a micro-level, its heterogeneity is derived from hydration performance that is governed by the type, particle size, hydraulic activity and amount of cement as well as that of supplementary cementing materials, the water-cement ratio (or water-binder ratio), the type and amount of admixtures and curing compounds and the method and effectiveness of curing. On a nano-level, its heterogeneity is derived from the petrographic/chemical characteristics of fine aggregate and that of non-hydraulic supplementary materials and the molecular structure of the hydrated cement paste. This multiple-level heterogeneity results both inherent (local) variability and spatial (regional) variability of the performance properties of concrete structures. Local variability can be usually analysed by classic mathematical statistical methods (repeatability conditions). Analysis of regional variability needs spatial models - that are typically used in geostatistics.

The ISO 3534-1 International Standard defines repeatability as the precision under conditions where independent test results are obtained with the same method on identical test items in the same laboratory by the same operator using the same equipment within short intervals of time (ISO 3534-1:2006). It means that repeatability gives information about how a person can repeat the measurement in the future similarly to that of the person carried out in the past. Therefore, repeatability is the spread of measurements made under the repeatability conditions (=measurement variability by the same operator); repeatability is a number that is unlikely to be exceeded by the difference between two measurements made under the repeatability conditions.

Repeatability is covered by other terms as well in the technical literature. In the nomenclature of e.g. ACI 228.1R-03 Committee Report "In-Place Methods to Estimate Concrete Strength" repeatability is referred 
as within-test variation (ACI 2003) and repeatability is sometimes called equipment variation in the technical literature (Ermer 2006).

During rebound hammer testing, separate testing locations are assigned on the concrete surface and multiple readings of the rebound index are recorded for each testing location. Usually, the average value of the multiple readings is considered as the specific value corresponding to a testing location. The uncertainty of the average value of the rebound index (either $\mathrm{R}$ or $Q$ value) depends on three influences: 1) the inherent and spatial variability of the strength of concrete within the structure tested; 2) the repeatability of the rebound hammer device used; 3 ) the number of individual readings at testing locations (ACI 2003).

Repeatability of the rebound hammers considerably depends on the actual design of the devices. Most important difference between the mechanical parts of the devices is the weight of the hammer mass. Original N-type Schmidt rebound hammers have a hammer mass of $380 \mathrm{~g}$, original L-type Schmidt rebound hammers have a hammer mass of $125 \mathrm{~g}$, Silver Schmidt rebound hammers have a hammer mass of $115 \mathrm{~g}$. The robust design of the original Schmidt hammers provide full protection to the mechanical parts by a solid metal housing. If the maintenance of the instrument is regular and its moving parts are kept clean, then failure and erroneous operation can only be expected if the operator is unskilled or not careful and implements a very severe operational error. The rebound index is recorded mechanically by an index rider that is moved by the hammer mass during rebound. The plastic housing Silver Schmidt rebound hammer has some operational differences. The operation principles (except for the lower weight hammer mass) is the same as that of the original instruments, however, the velocity of the hammer mass is measured by an optical measuring transformer. The light is modulated by the grooves on the circumference of the hammer mass and transmitted to a photodiode. The duration of the impact/ rebound periods is expressed by the ratio of the velocities. Since the hammer mass of the Silver Schmidt rebound hammer is of less weight, it runs the forth and back paths quicker. The weight of the plunger of the device is also smaller than that of the original Schmidt rebound hammer. Due to the introduced differences, the Q rebound index (Silver Schmidt rebound ham$\mathrm{mer}$ ) is greater than the $\mathrm{R}$ rebound index (original
Schmidt rebound hammer) and the repeatability and reproducibility of the devices is expected to be different as well. Limited information can be found in the technical literature regarding these questions.

One representative example can be introduced here from the technical literature in which natural stones were tested at 15 sites (in South Africa and in southern England) with original Schmidt rebound hammer and Silver Schmidt rebound hammer (together with further hardness testing instruments) on vertical and horizontal surfaces of different rock types with varying degrees of hardness (Viles et al. 2010). Each set of measurements was collected from an area of $30 \mathrm{~cm} \times 30 \mathrm{~cm}$ to avoid repeat blows to any single point. It was demonstrated that the Silver Schmidt rebound hammer tended to give characteristically larger variability than the original Schmidt rebound hammer. Based on the published results (Viles et al. 2010), it can be summarized that:

- Silver Schmidt rebound hammer has resulted 1.3 to 3.6-times larger coefficient of variation in the recorded rebound indices compared to the original Schmidt rebound hammer,

- Silver Schmidt rebound hammer has resulted 1.25 to 2.5 -times larger range in the recorded rebound indices compared to the original Schmidt rebound hammer,

- Silver Schmidt rebound hammer has resulted 1.8 to 13 -times larger sample size necessary to arrive at the same (5\% or $10 \%)$ confidence level of the estimation of the sample mean compared to the original Schmidt rebound hammer.

Viles et al. (2010) supposed that the observed large differences can be attributed to the fact that $\mathrm{N}$ type original Schmidt rebound hammer and L-type Silver Schmidt rebound hammer was used in their studies.

Another study has been made under laboratory conditions to compare the repeatability of different rebound hammers during testing of hardened concrete (Szilágyi et al. 2013). Eleven standard cubes $(150 \mathrm{~mm})$ of the same concrete composition $\left(f_{\mathrm{cm}}=64.7 \mathrm{~N} / \mathrm{mm}^{2}\right)$ were studied by an L-type original Schmidt rebound hammer, an N-type original Schmidt rebound hammer and an N-type Silver Schmidt rebound hammer capable to record both $\mathrm{R}$ rebound index and $\mathrm{Q}$ rebound index. Twenty rebound index recordings were taken by each device on each specimen that were fixed 
into a laboratory testing machine to provide a fix support. It was observed that the rebound indices can be recorded at a larger uncertainty in case of lower impact energy: the standard deviation and the coefficient of variation of the rebound indices of the L-type original Schmidt rebound hammer is larger than that of the N-type original Schmidt rebound hammer. It was also observed that the electro-optical recording of the N-type Silver Schmidt rebound hammer involves considerable uncertainty: the uncertainty of the Q rebound index is about $20 \%$ larger and the uncertainty of the $\mathrm{R}$ rebound index is $50-60 \%$ larger than that of the $\mathrm{R}$ rebound index provided by the $\mathrm{N}$-type original Schmidt rebound hammer (Szilágyi et al. 2013). It was demonstrated that the measurement uncertainty of the N-type Silver Schmidt rebound hammer is inferior to even the L-type original Schmidt rebound hammer. It can be supposed that the measurement uncertainty is related to the weight of the hammer mass in a more pronounced way than to the impact energy of the testing device. This supposition is further studied in the present paper.

\section{Role of geostatistical methods in structural diagnostics}

Geostatistical methods are widely used in mining, geology, soil science, environmental science, hydrology, meteorology and recently in engineering sciences for remote sensing, surface texture modelling, reliability and risk analysis, service life design and data assessment of non-destructive testing results (Balaguer et al. 2010; Goovaerts 1999; Li et al. 2014; Mlynarczuk 2010; Stewart, Mullard 2007; Tutmez, Hatipoglu 2007; Webster, Oliver 2007). The spatial variability analysis is well-described in the geostatistical literature for a long time; the geostatistical literature is very rich and several well known textbooks are widely available. Use of the geostatistical methods for concrete structures is, however, still very much limited today that can not be explained easily, considering the importance of the spatial variability of performance properties of concrete structures in structural diagnostics (GomezCardenas et al. 2013; Nguyen et al. 2013).

In situ NDT assessment of concrete structures may target strength estimation of structural concrete either to complete destructive testing or as being the only tool in the absence of drilled cores. In-situ assess- ment is frequently initiated by corrosion problems. In a practical situation, when eventually weaker regions of structural concrete within the structural element are present, it can be interesting to know that at which extent and in which directions the discrepancy is present and has influence on the performance properties. Geostatistical approaches can be adapted for the analysis of spatial variation. Geostatistics deals with spatially autocorrelated data (autocorrelation $=$ correlation between elements of a series and others from the same series separated from each other by a given interval) and usually assumes that the differences between the values of samples are determined by the relative spatial distance of the samples and the mean and variance of the differences depend only on the relative distance. Autocorrelation can be assumed for the performance properties of concrete structures as well.

Variograms are the main tools of geostatistics and they can provide - under particular conditions - an acceptable measure for spatial variability. Empirical variograms consist of empirical semivariances corresponding to a finite set of discrete lags. If empirical variograms indicate visible (apparent) sill and nugget then variogram models can be fit to the empirical data and modelling of the random field becomes possible.

As of today, the spatial variability analysis of concrete structures by geostatistical approaches is a terra incognita and basic research is needed to be initiated to reveal those methods and directions of assessment that can be the most useful in the spatial variability analysis of the performance properties of concrete structures.

\section{Research highlights}

Features of the performance properties of concrete structures are the product of many interacting physical and chemical processes. Part of these processes can be modelled with simplifying assumptions, but their interactions are so complex that the resultant variation can be considered to be random. The complexity and incomplete understanding of random processes result that neither deterministic nor theoretical solution is available that can quantify the resultant variation of the performance properties of concrete structures.

In the present case study it is not our priority to model the performance properties of concrete structures as random fields, at the available level of knowledge. Driven by the basic research nature of the study, 
the main aim is firstly to find suitable types of variogram or other spatial dependence measures that can be used in future spatial variability analysis for the performance properties of concrete structures. Most important aim is to study spatial variability of rebound hardness measurements with a detailed comparison of inherent variability parameters. It is also a major aim of the study to compare variability parameters of rebound indices recorded with different rebound hammers since a new, digital recording testing device appeared on the market recently, for which very limited in-situ measurement data are available in the technical literature. Main challenge of the present research is to study an almost completely unexplored field, spatial assessment of in-situ performance properties of concrete, and to be able to find possible methods for the spatial variability analysis of concrete structures that is considered currently one of the top priority targets in the assessment of concrete structures by NDT methods.

\section{Experimental observations}

A $6.5 \mathrm{~m}^{2}$ testing area of a reinforced concrete structural wall was selected for a comparative spatial analysis of surface hardness of structural concrete. The testing area is a selected part of a $50 \mathrm{~m}$ long and $8.0 \mathrm{~m}$ tall structural wall located in a production hall of an industrial facility in Hungary, built during 2013 (exact location is not given in this paper due to the aim of the owner). The structural wall has a thickness of $20 \mathrm{~cm}$ with prefabricated reinforcing steel mesh on both sides. Design concrete strength class of the ready mixed con- crete was $\mathrm{C} 20 / 25$. The concrete was transported into the formwork by concrete pumps during construction, and the compaction was carried out by poke vibrators. In-situ tests were performed on the wall at the age of concrete about six months. The testing area was selected at a nicely finished location of the wall where no placing joints were observable. Three non-destructive testing devices were used: an L-type original Schmidt rebound hammer (impact energy of $0.735 \mathrm{Nm}$; hammer mass of $125 \mathrm{~g}$ ), an N-type original Schmidt rebound hammer (impact energy of $2.207 \mathrm{Nm}$; hammer mass of $380 \mathrm{~g}$ ) and an N-type Silver Schmidt rebound hammer (impact energy of $2.207 \mathrm{Nm}$; hammer mass of $115 \mathrm{~g})$. Three different raster sizes were applied to assign the testing locations over the $6.5 \mathrm{~m}^{2}$ testing area: $0.15 \mathrm{~m}, 0.30 \mathrm{~m}$ and $0.60 \mathrm{~m}$. The testing area was selected to be small enough to avoid the eventual influence of large spatial variability due to the use of possibly different batches of concrete during construction (nevertheless no visible placing joints were observed on the surface, as indicated above) or the influence of gravity settlement in vertical direction, however, the testing area was selected to be large enough containing acceptable number of testing locations to be able to compare the different testing devices. Ten individual rebound index values were recorded at each testing location by each testing device. Tests were performed by the same operator for a given testing device. The arrangements of the testing locations together with the average values of the rebound indices corresponding to the testing locations are given in Figures 1-3.

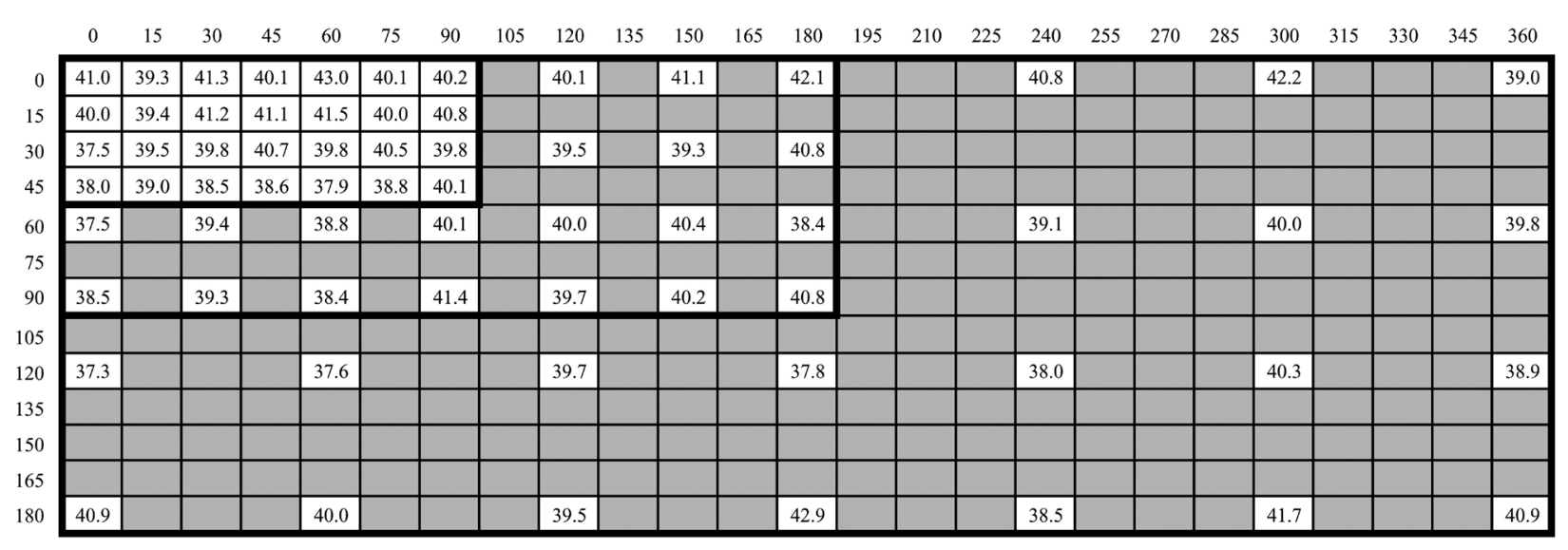

Fig. 1. Arrangement of the testing locations together with the average values of the rebound indices for the L-type original Schmidt rebound hammer 


\begin{tabular}{|c|c|c|c|c|c|c|c|c|c|c|c|c|c|c|c|c|c|c|c|c|c|c|c|c|}
\hline 0 & 15 & 30 & 45 & 60 & 75 & 90 & 105 & 120 & 135 & 150 & 165 & 180 & 195 & 210 & 225 & 240 & 255 & 270 & 285 & 300 & 315 & 330 & 345 & 360 \\
\hline 43.0 & 42.3 & 42.1 & 45.4 & 42.6 & 43.4 & 45.8 & & 44.2 & & 44.7 & & 43.7 & & & & 45.0 & & & & 42.7 & & & & 41.2 \\
\hline 42.5 & 42.0 & 42.6 & 44.5 & 45.0 & 44.3 & 45.6 & & & & & & & & & & & & & & & & & & \\
\hline 41.6 & 41.5 & 44.1 & 44.5 & 43.6 & 42.6 & 45.7 & & 42.7 & & 44.7 & & 45.1 & & & & & & & & & & & & \\
\hline 40.8 & 39.0 & 43.4 & 43.6 & 43.6 & 42.6 & 44.8 & & & & & & & & & & & & & & & & & & \\
\hline 38.6 & & 42.8 & & 40.7 & & 43.4 & & 43.0 & & 44.7 & & 41.3 & & & & 42.9 & & & & 42.9 & & & & 40.9 \\
\hline 75 & & & & & & & & & & & & & & & & & & & & & & & & \\
\hline 42.0 & & 42.3 & & 42.6 & & 42.2 & & 42.2 & & 44.0 & & 40.9 & & & & & & & & & & & & \\
\hline 105 & & & & & & & & & & & & & & & & & & & & & & & & \\
\hline 37.5 & & & & 40.4 & & & & 40.9 & & & & 41.5 & & & & 40.7 & & & & 44.1 & & & & 41.2 \\
\hline 135 & & & & & & & & & & & & & & & & & & & & & & & & \\
\hline 150 & & & & & & & & & & & & & & & & & & & & & & & & \\
\hline 165 & & & & & & & & & & & & & & & & & & & & & & & & \\
\hline 41.5 & & & & 43.2 & & & & 42.3 & & & & 41.5 & & & & 41.9 & & & & 43.1 & & & & 42.4 \\
\hline
\end{tabular}

Fig. 2. Arrangement of the testing locations together with the average values of the rebound indices for the N-type original Schmidt rebound hammer

\begin{tabular}{|c|c|c|c|c|c|c|c|c|c|c|c|c|c|c|c|c|c|c|c|c|c|c|c|c|c|}
\hline & 0 & 15 & 30 & 45 & 60 & 75 & 90 & 105 & 120 & 135 & 150 & 165 & 180 & 195 & 210 & 225 & 240 & 255 & 270 & 285 & 300 & 315 & 330 & 345 & 360 \\
\hline 0 & 44.3 & 43.2 & 42.8 & 38.8 & 42.6 & 40.2 & 42.8 & & 43.0 & & 38.6 & & 40.6 & & & & 41.1 & & & & 42.6 & & & & 44.4 \\
\hline 15 & 43.9 & 40.2 & 43.1 & 38.6 & 39.7 & 41.8 & 43.3 & & & & & & & & & & & & & & & & & & \\
\hline 30 & 42.4 & 41.3 & 40.6 & 41.6 & 42.2 & 42.4 & 42.7 & & 41.1 & & 42.2 & & 41.6 & & & & & & & & & & & & \\
\hline 45 & 43.5 & 44.1 & 42.0 & 45.1 & 43.9 & 45.5 & 45.9 & & & & & & & & & & & & & & & & & & \\
\hline 60 & 43.9 & & 42.5 & & 46.3 & & 43.6 & & 44.4 & & 43.5 & & 42.1 & & & & 45.5 & & & & 45.6 & & & & 48.4 \\
\hline 75 & & & & & & & & & & & & & & & & & & & & & & & & & \\
\hline 90 & 43.3 & & 43.0 & & 45.6 & & 43.3 & & 45.3 & & 42.4 & & 40.9 & & & & & & & & & & & & \\
\hline 105 & & & & & & & & & & & & & & & & & & & & & & & & & \\
\hline 120 & 41.0 & & & & 44.3 & & & & 43.4 & & & & 43.5 & & & & 46.9 & & & & 46.6 & & & & 46.3 \\
\hline 135 & & & & & & & & & & & & & & & & & & & & & & & & & \\
\hline 150 & & & & & & & & & & & & & & & & & & & & & & & & & \\
\hline 165 & & & & & & & & & & & & & & & & & & & & & & & & & \\
\hline 180 & 42.7 & & & & 43.5 & & & & 44.5 & & & & 41.2 & & & & 45.8 & & & & 41.4 & & & & 46.7 \\
\hline
\end{tabular}

Fig. 3. Arrangement of the testing locations together with the average values of the rebound indices for the N-type Silver Schmidt rebound hammer

\section{Discussion}

Repeatability and reproducibility of rebound hammer data can be studied by a comparison of standard deviation $\left(s_{R}\right)$, coefficient of variation $\left(V_{R}\right)$, range $\left(r_{R}\right)$ and relative range $\left(\rho_{R}\right)$ of individual rebound index readings corresponding to the testing locations (formulae are given in Appendix). As a rough estimation, it can be considered that the measurement uncertainty of a given rebound hammer device is lower if the values of the above statistical parameters are lower for the same testing location. Calculated results for the present experiments are given in Figure 4. The following keys are applied in the graphical representation in Figure 4: letter $a$ in the bar charts indicates results that correspond to the testing locations assigned over the $0.15 \mathrm{~m}$ distance raster points (total of 28 testing locations); letter $b$ in the bar charts indicates results that correspond to the testing locations assigned over the $0.15 \mathrm{~m}$ and 0.30 $\mathrm{m}$ distance raster points together (total of 48 testing locations); letter $c$ in the bar charts indicates results that correspond to all testing locations (total of 68 testing locations). Therefore, three bars are represented for each rebound hammer device (indicated as N, L and S, respectively) in each diagram. Numerical values given for the bars represent the average values of the statistical parameters that correspond to the 28,48 or 68 testing locations, respectively. It can be observed that all the four statistical parameters show the same trend for a given type of rebound hammer device related to the number of testing locations analysed. All the four statistical parameters can be considered to be appropriate for the repeatability comparisons. Reproducibility analysis is not possible for the present experiments since the tests were performed by the same operator for a given testing device. Results confirm the supposition that the measurement uncertainty is related to the weight of the hammer mass by revealing correlation with the studied statistical parameters. Lowest values of the selected four statistical parameters can be found for the N-type original Schmidt rebound hammer 
a)

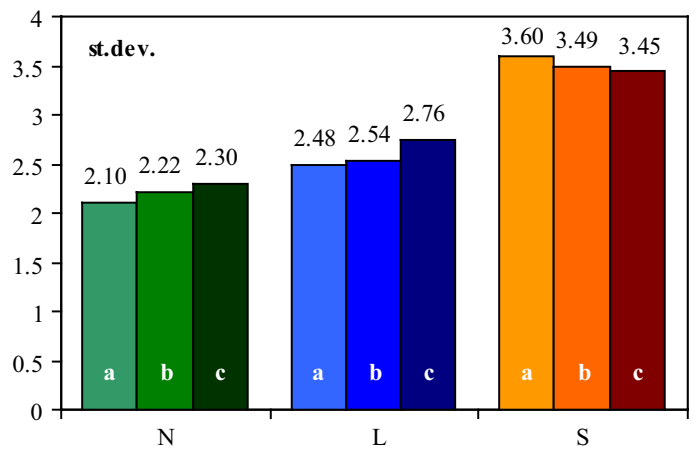

b)

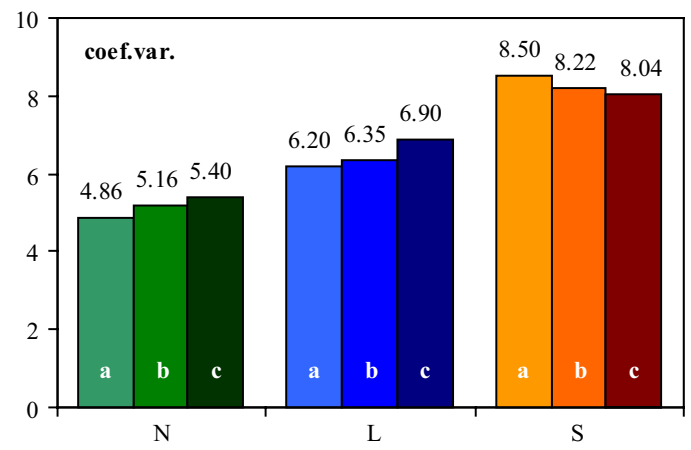

c)

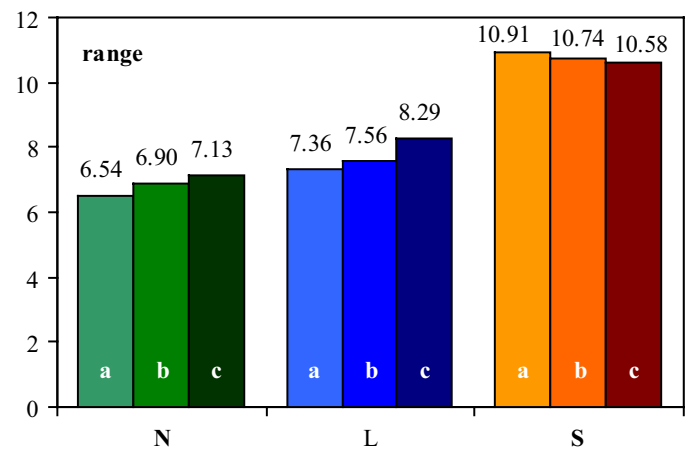

d)

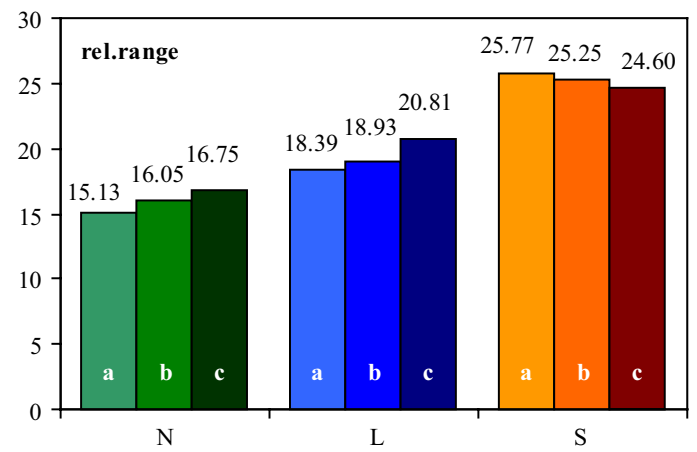

Fig. 4. a - standard deviation $\left(s_{R}\right)$ of individual rebound index readings corresponding to the testing locations; $\mathrm{b}$ - coefficient of variation $\left(V_{R}\right)$ of individual rebound index readings corresponding to the testing locations; $\mathrm{c}$ - range $\left(r_{R}\right)$ of individual rebound index readings corresponding to the testing locations; $\mathrm{d}$ - relative range $\left(\rho_{R}\right)$ of individual rebound index readings corresponding to the testing locations

(hammer mass of $380 \mathrm{~g}$; the highest in the present experiments) and highest values of the selected four statistical parameters can be found for the N-type Silver Schmidt rebound hammer (hammer mass of $115 \mathrm{~g}$; the lowest in the present experiments). It can be observed that decrease in the hammer mass results increase in the measurement uncertainty. It can be also realised that the impact energy of the rebound hammer devices apparently does not influence the measurement uncertainty since both the N-type original Schmidt rebound hammer and the N-type Silver Schmidt rebound hammer applies impact energy of $2.207 \mathrm{Nm}$. Influence of impact energy is realised in the absolute value of the rebound indices that can be seen in Figure 5 (keys applied are the same as for Figure 4). It can be seen that the lower is the impact energy of a device the lower is the absolute value of the rebound index.

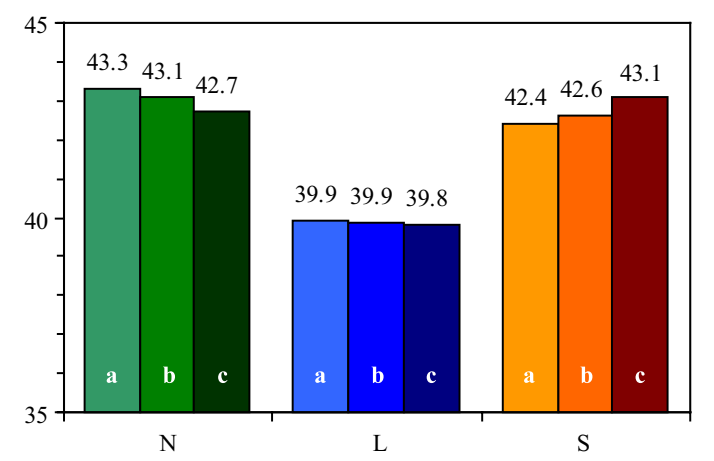

Fig. 5. Average rebound index readings corresponding to the testing locations

Results highlight the question of consistency of data as well. It can be generally supposed that the compressive strength of concrete and the surface hardness of concrete should be in the same relationship with any rebound index, independently from the hammer mass or the impact energy of a device; i.e. higher compressive strength, therefore, higher surface hardness of concrete should result higher rebound index. As a consequence, if different rebound indices are compared to each other then a positive correlation should be observed between them. Based on the present experiments, it is possible to prepare such comparisons as given in Figure 6. Diagrams indicate the average values of the rebound indices for all the 68 individual testing locations as data pairs of original L-type vs. original N-type, original L-type vs. Silver $\mathrm{N}$-type, and original $\mathrm{N}$-type vs. Silver $\mathrm{N}$-type rebound indices, respectively. It can be observed that (despite the relatively small overall ranges of the values) a rather strong positive correlation is formed between the original L-type and original $\mathrm{N}$-type rebound indices, however, the Silver N-type rebound index shows negative correlation with the other two rebound indices. 
a)

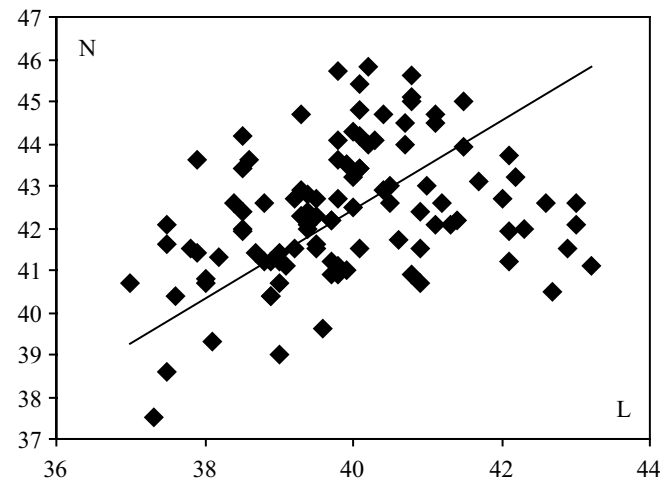

b)

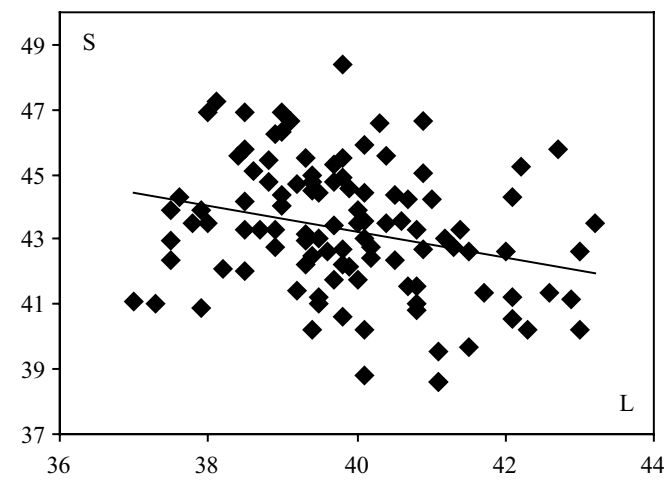

c)

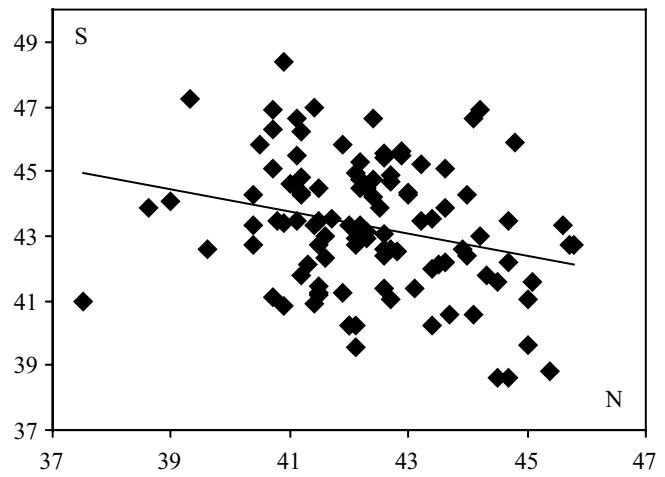

Fig. 6. a - correlation between rebound indices recorded by L-type and N-type original Schmidt rebound hammers for the individual testing locations; $\mathrm{b}$ - correlation between rebound indices recorded by L-type original Schmidt and N-type Silver Schmidt rebound hammers for the individual testing locations; c - correlation between rebound indices recorded by N-type original Schmidt and N-type Silver Schmidt rebound hammers for the individual testing locations

Since no malfunction of the devices was observed during the present experiments and the surface of the concrete did not indicate considerable variation in composition or compaction, therefore, the observed behaviour does not have a satisfying explanation. Earlier experiences of the author do not confirm the present observations either. Future work is needed if this observation is tendentious or not.

Considering the rebound hammer test, it can be assumed that the rebound index reading sets of sepa- rate testing locations are independent and identically distributed (i.i.d.) random variables since it can be supposed that the probability distribution of the rebound index does not change by location within the same structure and the separate testing locations can be considered to be mutually independent (Szilágyi et al. 2014). Based on these assumptions, the central limit theorem applies for the rebound hammer test; i.e. the probability distribution of the resultant of the rebound index reading sets of separate testing locations (each with finite mean and finite variance) approaches the normal distribution if sufficiently large number of the i.i.d. random variables is available. The overall empirical frequency histograms of the individual rebound indices (no separation by location)are indicated in Figure 7 together with the best goodness of fit probability density functions for the three non-destructive testing devices used. It can be realized that the resultant of the 68 independent testing locations apparently approaches rather well to the normal distribution in case of the $\mathrm{N}$-type original Schmidt rebound hammer. The results evidently confirm the accuracy of the operator sensory reading during the present tests. Strong skewness is observed for the L-type original Schmidt rebound hammer data that indicates the resultant of the 68 independent testing locations apparently approaching to the lognormal distribution rather than the normal distribution. The reason may be the lower hammer mass instrumented into the device. A skewed and apparently truncated shape of the frequency histogram and of the fitted probability density function is observed for the $\mathrm{N}$-type Silver Schmidt rebound hammer that indicates the resultant of the 68 independent testing locations apparently not approaching to the normal distribution. The reason of the behaviour is on one hand may be attributed to the lower hammer mass instrumented into the device (resulting the skewness), and on the other hand, to the electro-optical reading and digital recording of the measured values (that may have lower accuracy during the electro-optical readings at higher velocities of the hammer mass or a built-in digital filter that cuts automatically the outlier readings collected due to the lower accuracy of the readings at higher velocities of the hammer mass). Results of the present studies confirm the best performance of the N-type original Schmidt rebound hammer in terms of stability and normality of data, compared with either L-type original Schmidt rebound hammer or N-type Silver Schmidt rebound hammer for the studied medium strength conventional concrete. 
a)

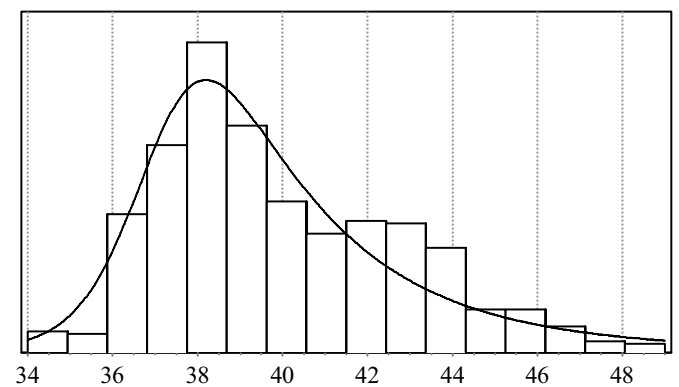

b)

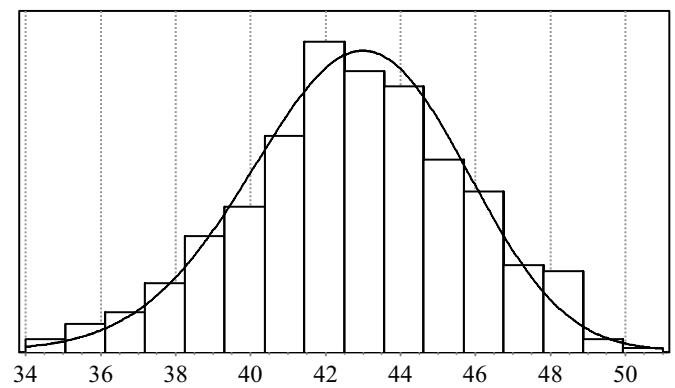

c)

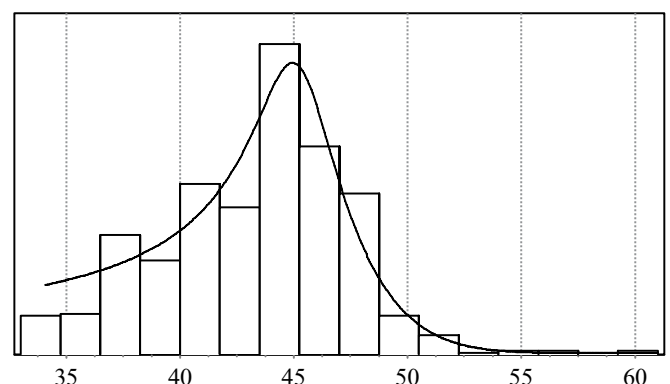

Fig. 7. a - overall empirical frequency histogram of the individual rebound indices (no separation by location) together with the best goodness of fit probability density function for the L-type original Schmidt rebound hammer; b - overall empirical frequency histogram of the individual rebound indices (no separation by location) together with the best goodness of fit probability density function for the $\mathrm{N}$-type original Schmidt rebound hammer; c - overall empirical frequency histogram of the individual rebound indices (no separation by location) together with the best goodness of fit probability density

function for the N-type Silver Schmidt rebound hammer

The recorded data make possible to prepare the empirical semivariograms for the mean values of the rebound index at the separate testing locations. Semivariogram is introduced in geostatistical spatial correlation analysis and plots correlation parameters of samples as the function of the separation between two spatial locations (referred to as lag; indicated with $\mathbf{h}$ in the present paper). An empirical semivariogram can be composed by the empirical semivariances of order 2 (see Appendix). Geostatistics usually assumes that the differences between the values of samples are determined by the relative spatial distance of the samples and the mean and variance of the differences depend only on the relative distance (Clark 2000). If a

semivariogram levels off (bounded), then a stationary random field can be used to model the observations (Breysse, Marache 2011). According to the geostatistical modelling nomenclature, the sill is the value of the actual correlation parameter at which the variogram levels off and the range is the lag distance over which the actual correlation parameter is constant. The range distance can be referred to as correlation distance, over which lag the values of the variable are not correlated (independent). The correlation distance indicates the degree of similarity of the variable between two points as a function of the distance that separates them. The nugget is the value of the actual correlation parameter at distances smaller than the minimum lag of observations (Webster, Oliver 2007).The nugget effect may provide information on strong differences in value within very short distances, or on a structural discontinuity, or on local material deterioration, or on an erroneous measurement.

The empirical semivariograms for the mean values of the rebound index at the separate testing locations are indicated in Figure 8 together with the best goodness of fit semivariogram models for the three nondestructive testing devices usedwith spherical semivariogram model or with linear semivariogram model. It can be observed that semivariograms are bounded for the N-type and L-type original Schmidt rebound hammers, and the correlation distances, the nuggets and the sills are showing rather close values if one applies the spherical semivariogram model. On the contrary, the semivariogram of the N-type Silver Schmidt rebound hammer does not level off, and a linear trend is applicable for the empirical semivariances. No correlation distance is visible. This unexpected statistical behaviour needs further experimental and theoretical analysis in the future.

\section{Open questions}

Different variograms are introduced in geostatistical spatial correlation analysis that plot different correlation parameters of samples as the function of the separation between spatial locations. It is possible to compose omnidirectional variograms by taking into account all pairs of data in any possible relative distance, and it is possible to compose unidirectional variograms by taking those pairs of data into account that correspond to a given direction. This latter method can be used to find anisotropy in the spatial variability in a 
practical situation and was outside the scope of the present study. The correlation distance, the sill and the nugget hold important information on the spatial variability both separately and together. Separately they can indicate different components of variability and the significance of those. Together they can be fit by variogram models that are essentially needed for the forming of prediction models.

Experimental results indicated that different variograms are possible to be constructed for in-situ rebound index readings collected on structural concrete elements, however, the correlation distances do not always give results that could have been explained by the

a)

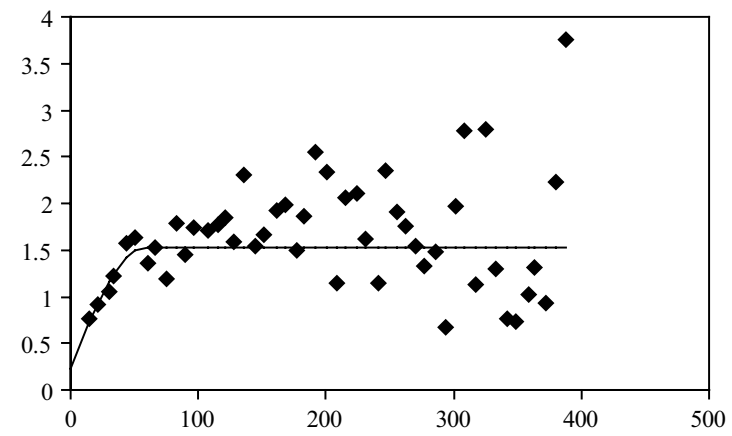

b)

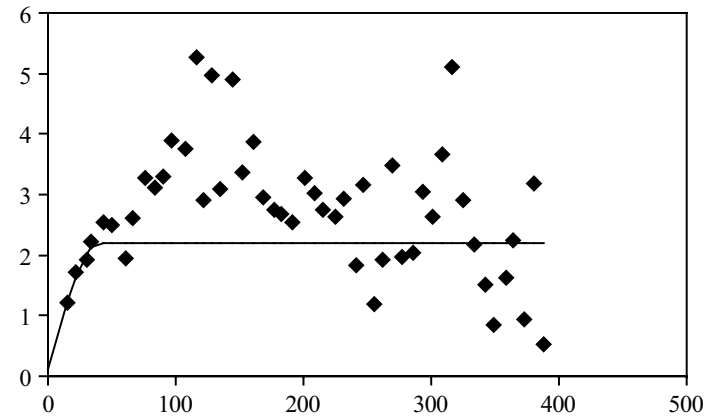

c)

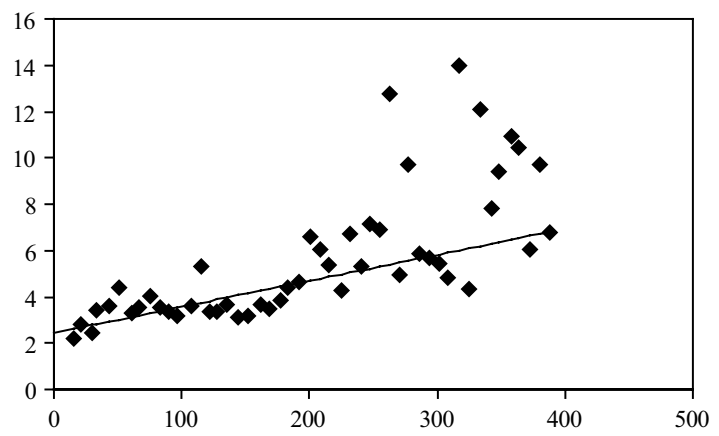

Fig. 8. a - empirical semivariogram together with the best goodness of fit spherical model for the recordings of L-type original Schmidt rebound hammer; b - empirical semivariogram together with the best goodness of fit spherical model for the recordings of N-type original Schmidt rebound hammer; c empirical semivariogram together with the best goodness of fit spherical model for the recordings of N-type Silver Schmidt rebound hammer performance realised. In the technical literature so few published data are available in this field that no suggestions can be made for direct future research based on the present level of knowledge. A possible influence of a dimensional size effect (and not of a statistical sample size effect that is well known for variograms) can be supposed that urges further studies. Idea of possible development of new spatial dependence measures that could perform better than the variograms in the spatial variability analysis of the performance properties of concrete structures also arises by available data.

Basic future research is needed in the spatial variability analysis of concrete structures by geostatistical approaches.

\section{Conclusions}

A reinforced concrete structural wall was studied in a comparative spatial analysis of surface hardness of structural concrete. Three non-destructive testing devices were used: an L-type original Schmidt rebound hammer (impact energy of $0.735 \mathrm{Nm}$; hammer mass of $125 \mathrm{~g}$ ), an N-type original Schmidt rebound hammer (impact energy of $2.207 \mathrm{Nm}$; hammer mass of $380 \mathrm{~g}$ ) and an N-type Silver Schmidt rebound hammer (impact energy of $2.207 \mathrm{Nm}$; hammer mass of $115 \mathrm{~g}$ ). Results confirmed that the measurement uncertainty is related to the weight of the hammer mass and the impact energy of the rebound hammer devices apparently does not influence the measurement uncertainty. It was realized that the measure of surface hardness for the Silver Schmidt rebound hammer (Q-value) does not have positive correlation to the original rebound index (R). Results confirmed the best performance of the N-type original Schmidt rebound hammer in terms of stability and normality of data. Geostatistical analysis of the measured data (in terms of empirical semivariograms) highlighted different statistical behaviour for the mechanical recording rebound hammers and for the electro-optical recording rebound hammer that urges further future research in the field of spatial variability analysis of concrete structures by geostatistical approaches.

\section{Acknowledgements}

The financial support of the OTKA (Hungarian Scientific Research Fund) is greatly appreciated for the research project No. OTKA K 109233. 


\section{References}

ACI. 2003. In-Place Methods to Estimate Concrete Strength. ACI 228.1R-03, Michigan: American Concrete Institute.

ACI. 2013. Nondestructive Test Methods for Evaluation of Concrete in Structures. ACI 228.2R-13. Michigan: American Concrete Institute.

Balaguer, A.; Ruiz, L. A.; Hermosilla, T.; Recio, J. A. 2010. Definition of a comprehensive set of texture semivariogram features and their evaluation for object-oriented image classification, Computers \& Geosciences 36(2): 231-240.

http://dx.doi.org/10.1016/j.cageo.2009.05.003

Brandestini, M. 2012. Method and apparatus for the non-destructive measurement of the compressive strength of a solid. United States Patent, Patent No.: US 8,261,620 B2, Date of Patent: 11 September 2012. $11 \mathrm{p}$.

Breysse, D.; Marache, A. 2011. Some estimates on the variability of material properties, in J. Baroth, F. Schoefs, D. Breysse (Eds.). Construction Reliability Safety, Variability and Sustainability. John Wiley \& Sons, 77-96.

Bungey, J. H.; Millard, J. H.; Grantham, M. G. 2006. Testing of concrete in structures. New York: Taylor and Francis. 352 p.

Clark, I. 2000. Practical geostatics. Geostokos Limited. ISBN 9780-9548911-1-4.

Ermer, D. S. 2006. Appraiser variation in gage R\&R measurement, Quality Progress 2006 May: 75-78.

Gomez-Cardenas, C.; Sbartaï, Z. M.; Balayssac, J. P.; Garnier, V.; Breysse, D. 2013. Spatial sampling optimization of non-destructive testing measurements, in $31^{\text {èmes }}$ Rencontres Universitaires de l'AUGC, ENS Cachan, 29-31 May 2013, Paris, France [online], [cited 20 May 2015]. Available from Internet: http://augc2013.ens-cachan.fr/Data/Articles/Contribution1187.pdf

Goovaerts, P. 1999. Geostatistics in soil science: state-of-the-art and perspectives, Geoderma 89(1-2): 1-45.

http://dx.doi.org/10.1016/S0016-7061(98)00078-0

ISO 3534-1:2006. Statistics - Vocabulary and symbols - Part 1: Probability and general statistical terms. International Standard.

Kolek, J. 1958. An appreciation of the Schmidt rebound hammer, Magazine of Concrete Research 10(28): 27-36.

Li, J.; Masia, M. J.; Stewart, M. G.; Lawrence, S. J. 2014. Spatial variability and stochastic strength prediction of unreinforced masonry walls in vertical bending, Engineering Structures 59: 787-797. http://dx.doi.org/10.1016/j.engstruct.2013.11.031

Malhotra, V. M. 1976. Testing hardened concrete: nondestructive methods: ACI Monograph, No. 9. Detroit: American Concrete Institute. $188 \mathrm{p}$.
Malhotra, V. M.; Carino, N. J. 2004. Handbook on nondestructive testing of concrete. $2^{\text {nd }}$ ed. CRC Press LLC. 384 p.

Mlynarczuk, M. 2010. Description and classification of rock surfaces by means of laser profilometry and mathematical morphology, International Journal of Rock Mechanics and Mining Sciences 47(1): 138-149.

http://dx.doi.org/10.1016/j.ijrmms.2009.09.004

Nguyen, N. T.; Sbartaï, Z. M.; Lataste, J. F.; Breysse, D.; Bos, F. 2013. Assessing the spatial variability of concrete structures using NDT techniques - Laboratory tests and case study, Construction and Building Materials 49: 240-250. http://dx.doi.org/10.1016/j.conbuildmat.2013.08.011

Proceq. 2007. Silver Schmidt operating instructions: Proceq SA Manual. 82034 101E ver 04 2008. Schwerzenbach. 48 p.

Schmidt, E. 1950. Der Beton-Prüfhammer, Schweizerische Bauzeitung 68(28): 378-379.

Stewart, M. G.; Mullard, J. A. 2007. Spatial time-dependent reliability analysis of corrosion damage and the timing of first repair for RC structures, Engineering Structures 29(7): 14571464. http://dx.doi.org/10.1016/j.engstruct.2006.09.004

Szilágyi, K.; Borosnyói, A.; Mikó, T. 2013. Comparison of the inherent variability in rebound hammer tests performed with different testing instruments, Építöanyag, Journal of Silicate Based and Composite Materials 65(3): 68-75. http://dx.doi.org/10.14382/epitoanyag-jsbcm.2013.14

Szilágyi, K.; Borosnyói, A.; Zsigovics, I. 2011. Rebound surface hardness of concrete: Introduction of an empirical constitutive model, Construction and Building Materials 25: 24802487. http://dx.doi.org/10.1016/j.conbuildmat.2010.11.070

Szilágyi, K.; Borosnyói, A.; Zsigovics, I. 2014. Extensive statistical analysis of the variability of concrete rebound hardness based on a large database of 60 years experience, Construction and Building Materials 53: 333-347.

http://dx.doi.org/10.1016/j.conbuildmat.2013.11.113

Szilágyi, K.; Borosnyói, A.; Zsigovics, I. 2015. Understanding the rebound surface hardness of concrete, Journal of Civil Engineering and Management 21(2): 185-192. http://dx.doi.org/10.3846/13923730.2013.802722

Tutmez, B.; Hatipoglu, Z. 2007. Spatial estimation model of porosity, Computers \& Geosciences 33(4): 465-475. http://dx.doi.org/10.1016/j.cageo.2006.07.008

Viles, H.; Goudie, A.; Grab, S.; Lalley, J. 2010. The use of the Schmidt Hammer and Equotip for rock hardness assessment in geomorphology and heritage science: a comparative analysis, Earth Surface Processes and Landforms 36: 320-333. http://dx.doi.org/10.1002/esp.2040

Webster, R.; Oliver, M. A. 2007. Geostatistics for environmental scientists. John Wiley \& Sons. ISBN 978-0-470-02858-2 


\section{Appendix}

\section{Formulae}

The following local statistical measures were calculated for the present analyses (in the formulae $R_{i}$ accounts for the individual rebound index readings and index $j$ denotes the $j^{\text {th }}$ testing location):

mean value (= arithmetic mean): $R_{m, j}=\frac{1}{n} \sum_{i=1}^{n} R_{i}$,

standard deviation:

$$
s_{R, j}=\left(\frac{1}{n-1} \sum_{i=1}^{n}\left(R_{i}-R_{m, j}\right)^{2}\right)^{1 / 2},
$$

coefficient of variation:

$$
V_{R, j}=\frac{s_{R, j}}{R_{m, j}} \cdot 100
$$

range:

$$
r_{R, j}=R_{i, \max }-R_{i, \min }
$$

relative range:

$$
\rho_{R, j}=\frac{r_{R, j}}{R_{m, j}} \cdot 100 .
$$

The following regional statistical measure was calculated for the spatial variability during the present analyses:

empirical semivariance: $\quad \gamma(\mathbf{h})=\frac{1}{2 N(\mathbf{h})} \sum_{i=1}^{N(\mathbf{h})}\left[f\left(\mathbf{u}_{i}+\mathbf{h}\right)-f\left(\mathbf{u}_{i}\right)\right]^{2}$,

where: $\mathbf{u}$ - vector of spatial coordinates (with $2 \mathrm{D}$ components $x$ and $y$ ); $f(\mathbf{u})$ - variable under consideration as a function of spatial location; $\mathbf{h}$ - lag vector representing separation between two spatial locations; $f(\mathbf{u}+\mathbf{h})-$ lagged value of variable under consideration; $N(\mathbf{h})$ - the number of data pairs separated by lag $\mathbf{h}$.

Adorján BOROSNYÓI. Civil engineer (MSc), PhD, associate professor at the BME Dept. of Construction Materials and Technologies. Main fields of interest: application of non-metallic (FRP) reinforcements for concrete structures, bond in concrete, nondestructive testing of concrete. 